\title{
The Development, Validation, and User Evaluation of Foodbook24: A Web-Based Dietary Assessment Tool Developed for the Irish Adult Population
}

Claire M Timon ${ }^{1 *}$, PhD; Richard J Blain ${ }^{1 *}$, MSc; Breige McNulty ${ }^{1}, \mathrm{PhD}$; Laura Kehoe ${ }^{2}$, MSc; Katie Evans ${ }^{2}, \mathrm{MSc}$ Janette Walton ${ }^{2}, \mathrm{PhD}$; Albert Flynn ${ }^{2}, \mathrm{PhD}$; Eileen R Gibney ${ }^{1}, \mathrm{PhD}$

${ }^{1}$ UCD, Institute of Food and Health, University College Dublin, Dublin, Ireland
${ }^{2}$ UCC, School of Food and Nutritional Sciences, University College Cork, Cork, Ireland
${ }^{*}$ these authors contributed equally

Corresponding Author:

Eileen R Gibney, PhD

UCD

Institute of Food and Health

University College Dublin

Sceince Centre South

Befield

Dublin, Dublin 4

Ireland

Phone: 35317162819

Fax: 35317161147

Email: eileen.gibney@ucd.ie

\section{Abstract}

Background: The application of technology in the area of dietary assessment has resulted in the development of an array of tools, which are often specifically designed for a particular country or region.

Objective: The aim of this study was to describe the development, validation, and user evaluation of a Web-based dietary assessment tool "Foodbook24."

Methods: Foodbook24 is a Web-based, dietary assessment tool consisting of a 24-hour dietary recall (24HDR) and food frequency questionnaire (FFQ) alongside supplementary questionnaires. Validity of the 24HDR component was assessed by 40 participants, who completed 3 nonconsecutive, self-administered 24HDR using Foodbook24 and a 4-day semi-weighed food diary at separate time points. Participants also provided fasted blood samples and 24-hour urine collections for the identification of biomarkers of nutrient and food group intake during each recording period. Statistical analyses on the nutrient and food group intake data derived from each method were performed in SPSS version 20.0 (SPSS Inc). Mean nutrient intakes (and standard deviations) recorded using each method of dietary assessment were calculated. Spearman and Pearson correlations, Wilcoxon Signed Rank and Paired $t$ test were used to investigate the agreement and differences between the nutritional output from Foodbook24 (test method) and the 4-day semi-weighed food diary (reference method). Urinary and plasma biomarkers of nutrient intake were used as an objective validation of Foodbook24. To investigate the user acceptability of Foodbook24, participants from different studies involved with Foodbook24 were asked to complete an evaluation questionnaire.

Results: For nutrient intake, correlations between the dietary assessment methods were acceptable to very good in strength and statistically significant (range $r=.32$ to .75). There were some significant differences between reported mean intakes of micronutrients recorded by both methods; however, with the exception of protein $(P=.03)$, there were no significant differences in the reporting of energy or macronutrient intake. Of the 19 food groups investigated in this analysis, there were significant differences between 6 food groups reported by both methods. Spearman correlations for biomarkers of nutrient and food group intake and reported intake were similar for both methods. A total of 118 participants evaluated the acceptability of Foodbook24. The tool was well-received and the majority, 67.8\% (80/118), opted for Foodbook24 as the preferred method for future dietary intake assessment when compared against a traditional interviewer led recall and semi-weighed food diary. 
Conclusions: The results of this study demonstrate the validity and user acceptability of Foodbook24. The results also highlight the potential of Foodbook24, a Web-based dietary assessment method, and present a viable alternative to nutritional surveillance in Ireland.

(J Med Internet Res 2017;19(5):e158) doi: 10.2196/jmir.6407

\section{KEYWORDS}

diet records; Internet; validity; biomarkers; method acceptability; adults

\section{Introduction}

\section{Background}

Dietary assessment methodologies are known to have both strengths and limitations [1]. Some of the methodological caveats among current dietary assessment methods include the participant burden, reliance on participant's honesty and ability to remember food and drinks consumed, and their individual portion sizes [2,3]. Cost, particularly when large-scale epidemiological studies and national nutrition surveys are concerned, can be another limiting factor [1]. The 24-hour dietary recall (24HDR) method is associated with low participant burden and can provide reliable intake data with minimal bias [3]. However, recalls can be expensive, time consuming to administer, and require skilled nutritionists or dietitians [4].

The application of technology in dietary assessment has made it possible to minimize the reliance on trained interviewers and instead facilitate automated self-administered 24HDR via Web-based platforms and mobile phone apps [5]. Web-based methodologies facilitate the collection of dietary intake across many geographic locations [6], from large cohorts [7], and are often preferred by participants compared with the traditional methods [8,9]. An example of a successful Web-based 24-hour recall tool is the ASA24 developed by the National Cancer Institute, USA. From its launch in 2009, more than 200 researchers have used ASA24 to carry out over 120,000 recalls [4].

\section{Biomarker Analysis}

A prerequisite for the acceptance and use of such Web-based dietary assessment tools is their validity. It is vital that new tools and methods measure what they are designed to measure. Assessing the relative validity of a new method or tool can be achieved by comparing intakes recorded by a new method to intakes derived from a method that is deemed more accurate [10]. The advent of biomarker analysis now also offers an objective measure of intake, which may overcome the bias associated with self-reported data [11]. Biomarkers of both nutrient and food intake can be analyzed in plasma, serum, and urine to indicate both short- and long-term intake and can provide an objective validation of dietary assessment tools as they reflect, but are independent of food intake. Although a feasible validation tool, biomarker analysis is not always included in the validation of new dietary assessment techniques, which is perhaps in part due to the invasive nature of sample collection and associated cost. Another common validation reference used is direct observation of participants during eating occasions that can then be compared with reported or recalled dietary intake data $[12,13]$. However, this too can be costly and can often take place in a laboratory setting, potentially influencing an individual's choices.

In a recent review of dietary assessment or tracker apps for mobile phones [14], the authors concluded that very few of the apps identified were based on scientifically valid nutrient composition databases and few had consulted nutrition professionals in the development process. With such unprecedented access to health and nutrition information the needs for scientifically validated, Web-based methods of dietary assessment are essential. The aim of this study was to describe the development, validation, and user evaluation of Ireland's first Web-based, self-administered 24HDR tool "Foodbook24."

\section{Methods}

\section{Foodbook24}

\section{The Development of Foodbook24}

The design of the Foodbook24 tool was informed by guidelines issued on the collection of dietary information that can be used to estimate nutrient intake and to assess exposure to biological agents and chemical substances by the European Food Safety Authority in 2009 [15]. In addition, interviews with key stakeholder organizations or institutions in Ireland and an extensive review of the literature concerning Web-based dietary assessment platforms were conducted to further inform the design of Foodbook24. The final proposed design of Foodbook24 was a self-administered, Web-based tool consisting of different independent components that facilitate the collection of dietary intake data without direct interaction with a researcher. These components include a screening and consent stage, demographic questionnaire, 2x24-hour multiple pass recall (administered on nonconsecutive days), food frequency, and food choice questionnaires, and finally a tool evaluation questionnaire. All of these stages occur at predetermined time points and have been developed independently of each other, meaning different parts of the tool could potentially be activated or deactivated depending on the requirements of any given survey or study.

For the dietary recall component of Foodbook24, the user is required to complete multiple passes (as described by Moshfegh et al [16]) to report their dietary intake for the previous 24-hour period. Initially, the user lists the meals and snacks consumed the previous day, reports the times that these meals were consumed (as depicted in Figure 1), and also the location of food preparation. The user then adds individual food and drink items to each of the defined meals or snacks using a free text search function to select food and drink items from a predefined database. Further questions known as "completeness of 
collection mechanisms" are presented to the user such as probe or linked food options and portion size information is then determined by selecting relevant amounts or portion size photographs. Finally, the user is presented with a review of selected items, a list of frequently forgotten foods, and queried about nutritional supplement intake and whether the reported intake was representative of usual intake. To populate the content of the Foodbook 24 tool, various databases, completeness of collection mechanisms, and questionnaires were developed. These included a food list, nutrient composition, nutritional supplements and portion size databases, completeness of collection mechanisms for the 24-hour recall component and various supplementary questionnaires such as demographic and food choice questionnaires. The processes and considerations surrounding these components of the tool are described below.

Figure 1. The meal information stage of Foodbook24.

\section{foodbooker}

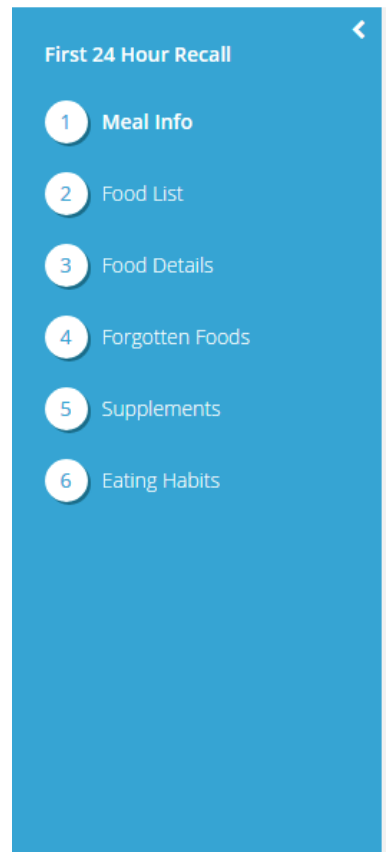

What meals did you have yesterday?

\section{Food List and Nutrient Composition}

The food and drink list used in Foodbook24 is a shortened list of food and drinks consumed in the Irish National Adult Nutrition Survey (NANS 2008-2010) [17]. The food composition data linked to the NANS dataset are derived from UK food composition tables [18] and the Irish Food Composition Database (IFCDB) [19]. The reduction process of the list involved the merging of food codes of a similar description and/or composition [20]. The aim of the reduction process was to reduce the food list that participants would have to search through to describe their dietary intake, thus reducing participant burden without compromising the nutrient composition output. This process significantly reduced the total number of food and drinks from 2552 to 751 individual items. An investigation into the agreement of the shortened food list to the original comprehensive list is reported elsewhere [20], but overall shows excellent agreement and was therefore deemed appropriate for inclusion in Foodbook24. The food and drink items were grouped into 58 different food groups and further categorized into 18 categories.

\section{Completeness of Collection Mechanisms}

On review of Web-based 24HDR tools, the use of "probe" and "linked" (as described by Foster [21]) food options are commonly used to ensure the complete capture of dietary intake data. Linked food options were added to 132 food and drink items within the Foodbook24 food and drink list (an example of a linked food option is highlighted in Figure 2). These options are linked to the primary selection and are a list of options known to be commonly consumed with the primary selection. The use of "probe questions," that is, questions posed to a respondent based on their primary food or drink selection provides more detail and further classifies that selection were implemented for 123 food and drink items (an example of a probe food question is depicted in Figure 3, where the user is asked to clarify whether the food item was homemade or retail). To improve the user experience of searching for food and drink items, "food tags" were applied to 484 of the 751 food and drink items. As the search function in this tool was based on the actual description of the food or drink item, "slang words" or brand names were tagged to the parent food to address common misspellings and multiple names of various food and drink items, for example, searching for "Houmus" would still retrieve "Hummus." 
Figure 2. The "linked food" options available for the primary food selection of chips within Foodbook24.

With your Chips, did you have any of the following?

\begin{tabular}{|l|l|}
\hline Vinegar & Add \\
\hline Tomato ketchup & Add \\
\hline Mayonnaise, regular & Add \\
\hline Other & Add \\
\hline
\end{tabular}

Figure 3. The food details stage of Foodbook24, presenting the user with a "probe question" and portion size images.

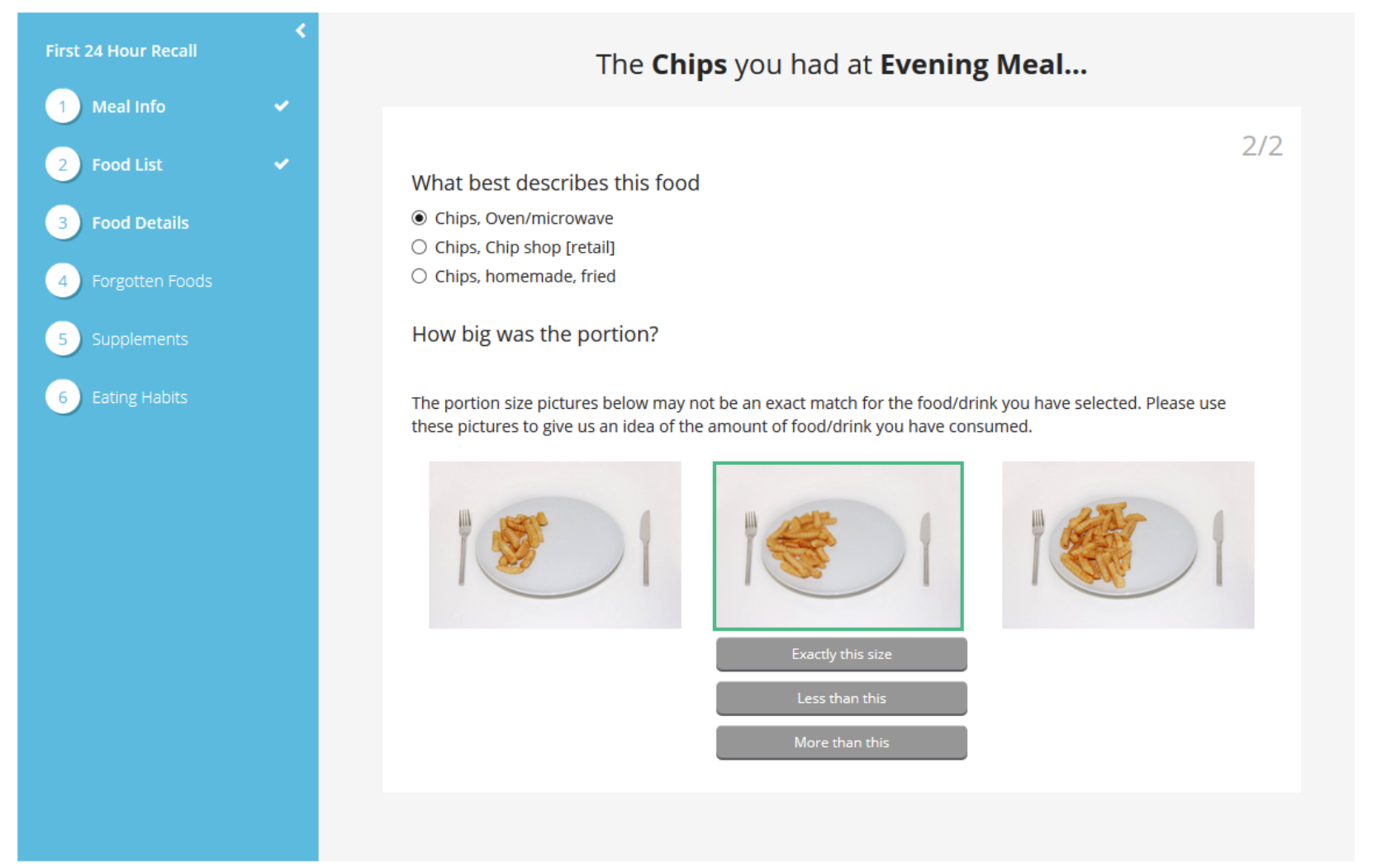

\section{Portion Size}

Portion size can be estimated in two different ways within Foodbook24. Building on an existing dataset of portion size images (created as part of the Food4me project) [6], 96 additional portion size images were created for Foodbook24. The range of food and drink weights for which the portion size images depict was based on ranges of weights consumed in NANS [17]. For the majority of food and drink items, there are a set of 3 portion size images representing small, medium, and large portions (although these terms were not alluded to in the tool) as shown in Figure 3. The respondent also had the option to select "less than this" for any of the 3 images in a set, "exactly this size" or "greater than this." Midpoint weights consumed in the NANS survey (eg, between small and medium portion size) underpin these options also. In Foodbook24, there are 174 sets of portion size images totaling 531 individual portion size images. For 195 food and drink items, average portion sizes from the Ministry for Agriculture, Fisheries and Food [22] were used. These are generally food items served in units such as cream crackers or biscuits; these were also followed by a question regarding how many serving of this item were consumed.

\section{Nutritional Supplements}

A database of 542 branded nutritional supplements with related nutrient composition was compiled to feature in the Foodbook24 tool. This nutritional supplement data consisted of supplements recorded as part of NANS [17] and those that were recorded as part of the Food4me study [6] by participants. These nutritional 
supplements were grouped into 26 supplement categories, for example, zinc supplements contains several different brands of zinc supplements for participants to choose from. An unknown or generic supplement composition option was also created using the median nutrient composition of all those supplements in that category.

\section{Supplementary Questionnaires}

The following components feature in the overall tool design; however, these components were not utilized in the validation study. A food frequency questionnaire (FFQ) was compiled for inclusion in the Foodbook24 tool based on EU Menu guidelines [15] and the Food4me FFQ [6]. The final questionnaire included 81 items and used the same frequency responses as featured in EPIC FFQ [23]; however, the Foodbook24 FFQ did not collect information on portion size. The FFQ was included in the tool to capture the intake of food and drink items less commonly consumed rather than contribute to nutrient intake. The food choice questionnaire [24] was also included as a multidimensional measure of motives related to food choice. The user is presented with a statement related to food choice such as, "It is important to me that the food I eat on a typical day contains a lot of vitamins and minerals" and can then agree or disagree with this using a 7-point scale. Screening, demographic, and evaluation questionnaires were built into the tool alongside a study information sheet and consent form, the contents of which can be easily changed depending on the use of the tool.

\section{Validation Study}

\section{Recruitment and Inclusion and Exclusion Criteria}

Ethical approval for the study was obtained through University College Dublin (UCD) Human Research Ethics Committee (LS-15-27-Gibney-Timon). Participants were recruited via email using UCD mailing lists, University societies, and posters around campus. Individuals who expressed an interest in the study were contacted by phone and screened for eligibility. Subjects were eligible if the individuals were aged 18-64 years, fluent in English, had regular access to the Internet, were not pregnant, did not have any disease or condition that required chronic therapeutic nutritional or medical treatment, and had not been enrolled in or completed a degree, $\mathrm{MSc}$ or $\mathrm{PhD}$ in Human Nutrition. In total, 55 participants signed-up to take part in the study; however, 15 dropped out, which left a final sample size of 40 .

\section{Study Design}

Participants were required to visit the Institute of Food and Health, UCD on three separate study visits during the study duration. At the first visit, informed consent, demographic information, and anthropometric measurements (including weight and body fat percentage and height) were collected. After the first visit, participants completed 3 nonconsecutive, unannounced, self-administered 24HDRs using the Web-based Foodbook24 tool. For this study, only the 24-h dietary component of the tool was used to record dietary intakes. Portion size photographs embedded in the tool depict a range of weights reported in NANS were used as portion size assessment aids. Emails were sent to participants on the morning and they were required to complete a recall using Foodbook24 without prior notice. In the middle of data collection using Foodbook24, participants attended study visit 2 and provided a fasting blood sample and a 24-hour urine collection. Following a 10-day wash out period, participants completed a 4-day semi-weighed food diary using a Tanita digital scale (KD-400) to weigh food and drink consumption as often as possible. On completion of this, participants attended the final study visit where they provided an additional fasting blood sample and 24-hour urine collection, completeness of check on their food diary, and completed a study evaluation questionnaire.

\section{Collection of Biological Samples}

Both blood and urine samples were collected from each participant in order to analyze specific biomarkers of nutrient intake. Blood samples $(2 \times 6 \mathrm{~mL})$ were collected into lithium heparin tubes following a $12 \mathrm{~h}$ fasting period. Samples were spun for $15 \mathrm{~min}$ at relative centrifugal force (RCF) 1500 at $4^{\circ} \mathrm{C}$. Plasma was transferred to labeled microtubes in $500 \mu \mathrm{L}$ aliquots, two of which contained $10 \%$ meta-phosphoric acid (MPA) for the stabilization of ascorbic acid. All plasma samples were then frozen at $-80^{\circ} \mathrm{C}$. Plasma samples were analyzed by Vitas Analytical Services (Norway) for the determination of plasma ascorbic acid, carotenoids, and fatty acid content. Participants also provided a 24-hour urine collection and were instructed to collect the sample according to the protocol outlined in the National Diet and Nutrition Survey [25]. The urine samples were subsequently analyzed for urinary urea (as an indicator of protein intake [26]) using Daytona RX Clinical Analyzer (Randox, Nishinomiya, Japan) and urinary sodium, potassium, and creatinine were measured using the Cobas Integra 700 Analyzer (Roche Diagnostics) by the Department of Clinical Chemistry at St Vincent's University Hospital. The ratio of observed over expected urinary creatinine excretion (UCE; creatinine index) [27] alongside other criteria such as reported $>1$ missed void and samples with a total volume $<0.5 \mathrm{~L}$ was used to exclude incomplete 24-hour urine collections from biomarker analysis [28].

\section{Data and Statistical Analysis}

Foodbook24 automatically generates a food and nutrient intake output for each user. The data from the semi-weighed food diaries was manually entered into WISP version 3 (Tinuviel Software, Anglesey, UK) by a single researcher in an attempt to maintain consistency and were reviewed independently by another researcher. Nutrient outputs for the semi-weighed food diaries were then generated. Mean daily nutrient intakes, standard deviations, and descriptive statistics (demographic data and evaluation questionnaire data) were computed in SPSS (version20) to determine the validity and user acceptability of Foodbook24. The normality of the data was assessed using the Shapiro-Wilk test before investigating the agreement between the dietary assessment methods, and parametric or nonparametric tests were used accordingly for subsequent analysis. Pearson and Spearman coefficient analyses was used to investigate the agreement between both methods in the reporting of nutrient intake, and to investigate the relationship between reported nutrient and food group intake and biological markers of intake. Correlation analysis was performed on energy 
adjusted data (nutrient intakes were energy-adjusted, that is, the percentage of energy intake for macronutrients and gram per milligram per milligram $(\mathrm{g} / \mathrm{mg} / \mathrm{mg})$ per $10 \mathrm{MJ}$ energy intake for micronutrients). Deattenuated correlation coefficients were also computed by multiplying the initial coefficient by $R_{1}$, this was calculated as follows: $\mathrm{R}_{1}=\mathrm{R}_{0} \sqrt{ }\left(1\left(\left(s w^{2}\right) /\left(s b^{2}\right)\right) / n\right)$, where $\left(s w^{2}\right) /\left(s b^{2}\right)$ is the ratio of the within- and between-person variances and $n$ is the number of replicates per person for the given variable. The within- and between-person variances were obtained from an analysis of variance (ANOVA) model Correlations coefficients were considered as follows: very good (0.7 and greater), good (0.5-0.69), acceptable (0.3-0.49), and poor (0.3 or less) [29].

The relative agreement between Foodbook 24 and the food diary was assessed using cross-classification of nutrient and food group intakes to estimate the percentage of participants who were classified by the two methods into quartiles of "exact agreement," "exact agreement plus adjacent," "disagreement," and "extreme disagreement." Bland and Altman [30] analysis was performed to assess the limits of agreement in the reporting of macronutrient intake, considering the two methods of dietary assessment to be comparable if greater than $95 \%$ of the data plots were within the limits of agreement. Wilcoxon Signed Rank and Paired Student $t$ test were used to identify the differences in the nutrient intake, and independent samples $t$ test were used to compare daily food group intakes reported by both methods.

\section{Evaluation of Foodbook24}

Participants involved in two studies that investigated both the comparability of Foodbook24 (relative to an interviewer led 24-hour recall, results of which are not included in this publication) and the validity of Foodbook24 (compared with a 4-day semi-weighed food diary) were asked to complete an evaluation questionnaire once the study had concluded. In total, 118 participants (58 male and 60 female aged between 18 and 62 years) completed the optional questionnaire, 40 participants from the validation study and 79 from the comparison study. The design of the evaluation questionnaire was based around questionnaires used in similar studies that investigated the user acceptability of technology-based dietary assessment tools $[31,32]$. The questionnaire consisted of a 16 -item evaluation questionnaire that was administered online. The focus of the questionnaire was to assess the participant's overall experience using the 24-hour recall component of the tool only (as participants did not use other components of the tool, eg, FFQ as part of these studies), and their acceptability of some of the software design features, method preference, and future use.

\section{Results}

\section{Study Population}

A total of 55 participants signed-up to complete the validation study, of which 15 participants withdrew and therefore did not complete the entire study (dropout rate of $27 \%$ ), with $\mathrm{N}=40$ completing. Of those that withdrew, 9 reported that the collection of biological samples was too burdensome, 3 could not attend the study visits due to prior commitments, and 3 did not disclose their reason for dropping out. This left a final sample size of 40 participants that completed the study; however, 1 participant was excluded from the analysis as he or she did not follow the study protocol correctly. Table 1 displays the demographic characteristics of participants $(n=39)$. The mean of age of participants was 32 years (age range 18-62 years). Over half of participants were either employed as staff $(46.2 \%)$ or enrolled as students $(10.3 \%)$ in UCD. The remainder of participants were either employed locally to the university or heard about the study through an Irish volunteer website. 
Table 1. Demographic characteristics of participants.

\begin{tabular}{|c|c|}
\hline Demographic characteristics & Mean (SD) or $\mathrm{n}(\%)$ \\
\hline \multicolumn{2}{|l|}{ Age and $\mathrm{BMI}^{\mathrm{a}}$, mean $(\mathrm{SD})$} \\
\hline Age (years) & $32.2(13.4)$ \\
\hline $\mathrm{BMI}^{\mathrm{a}}\left(\mathrm{kg} / \mathrm{m}^{2}\right)$ & $24.40(3.75)$ \\
\hline \multicolumn{2}{|l|}{ Gender, n (\%) } \\
\hline Female & $20(51)$ \\
\hline Male & $19(49)$ \\
\hline \multicolumn{2}{|l|}{ Occupation, n (\%) } \\
\hline Student & $4(10)$ \\
\hline University staff & $18(46)$ \\
\hline Employed outside of the University & $16(41)$ \\
\hline Unemployed & $1(3)$ \\
\hline \multicolumn{2}{|l|}{ Smoking habits, n (\%) } \\
\hline Smoker & $4(10)$ \\
\hline Nonsmoker & $29(74)$ \\
\hline Ex-smoker & $6(16)$ \\
\hline \multicolumn{2}{|l|}{ Medical conditions, $\mathrm{n}(\%)$} \\
\hline None & $25(65)$ \\
\hline One or more & $14(35)$ \\
\hline
\end{tabular}

${ }^{\mathrm{a}} \mathrm{BMI}$ : body mass index.

${ }^{\mathrm{b}} \mathrm{SD}$ : standard deviation.

\section{Comparison of Nutrient Intake Reported by Both Methods of Dietary Assessment}

The unadjusted, mean daily intakes for energy, nutrients, and food groups recorded using Foodbook24 and a semi-weighed food diary are displayed in Multimedia Appendix 1 and Table 2 . The energy adjusted correlations, deattenuated correlations, mean difference, and the limits of agreement ( 2 standard deviations of the mean) between the two methods for the reporting of nutrients are also displayed in Multimedia Appendix 1. For nutrient intake, the majority of correlations between the dietary assessment methods ranged from acceptable to very good, and are statistically significant (range $r=.32$ to .75 ). 
Table 2. Food group intakes recorded by participants using the Foodbook24 tool and a 4-day semi-weighed food diary.

\begin{tabular}{|c|c|c|c|}
\hline Food group & $\begin{array}{l}\text { Foodbook24 }(\mathrm{g}), \\
\text { mean }\left(\mathrm{SD}^{\mathrm{a}}\right)\end{array}$ & $\begin{array}{l}\text { Food diary }(\mathrm{g}) \text {, } \\
\text { mean }(\mathrm{SD})\end{array}$ & $P$ value \\
\hline Grains, rice, pasta, and savories & $207(111.5)$ & $171(127.1)$ & .20 \\
\hline Bread and rolls & $90.4(54.54)$ & $102(46.29)$ & .31 \\
\hline Breakfast cereals & $119(83.9)$ & $86.7(80.99)$ & .09 \\
\hline Biscuits, cakes, and pastries & $52.9(36.67)$ & $50.7(44.68)$ & .82 \\
\hline Milk and yogurt & $192(228.4)$ & $346(223.4)$ & .05 \\
\hline Creams, ice creams, and desserts & $67.0(70.5)$ & $73.7(70.86)$ & .8 \\
\hline Cheeses & $25.2(13.40)$ & $35(16.1)$ & $<.01^{\mathrm{b}}$ \\
\hline Butter, spreading fats, and oils & $14.93(7.74)$ & $10.42(9.77)$ & $<.05^{\mathrm{b}}$ \\
\hline Eggs and egg dishes & $98.3(69.61)$ & $80.2(52.68)$ & .26 \\
\hline Potatoes and potato dishes & $135(95.4)$ & $147(128.5)$ & .66 \\
\hline Veg and veg dishes & $172(107.5)$ & $237(152.5)$ & $<.05^{\mathrm{b}}$ \\
\hline Fruit and fruit dishes & $372(264.3)$ & $252(130.5)$ & $<.01^{\mathrm{b}}$ \\
\hline Fish and fish dishes & $54.6(58.23)$ & $101(102.0)$ & .05 \\
\hline Meat and meat products & $244(141.9)$ & 249 (179.7) & .62 \\
\hline Alcoholic beverages & $1314(1208.2)$ & $667(761.5)$ & .09 \\
\hline Beverages other (sugar-sweetened) & $1855(1160.1)$ & $1516(854.7)$ & .14 \\
\hline Sugars, confectionary, preserves, and savory snacks & $81.9(50.81)$ & $54.4(47.63)$ & $<.01^{\mathrm{b}}$ \\
\hline Soups, sauces, and miscellaneous foods & $91.8(96.85)$ & $130(120.0)$ & .13 \\
\hline Nuts, seeds, herbs, and spices & $16.8(20.24)$ & $37.4(36.61)$ & $<.001^{\mathrm{b}}$ \\
\hline
\end{tabular}

${ }^{\mathrm{a}} \mathrm{SD}$ : standard deviation.

${ }^{\mathrm{b}}$ Significant difference in the reporting of food group intake between the two dietary assessment methodologies as defined by independent samples $t$ test.

However, some correlation coefficients were not statistically significant including monounsaturated fat $(r=.308, \mathrm{n}=39, P=.05)$. Of the 34 nutrients investigated, there were significant differences between the reported mean intakes of 11 nutrients reported by the two methods; however, with the exception of protein $(P=.02)$, there were no significant differences in the reporting of energy and macronutrient intake. Deattenuated correlation coefficients were higher, but the improvement was modest with the exception of intakes of fat $(\mathrm{g} / \mathrm{d})$.

Bland and Altman (Figures 4-8) analysis was used to further investigate the agreement between and the semi-weighed food diary. For macronutrients, Foodbook 24 reported slightly lower intakes than the food diary; however, $95 \%$ or more of the data cases fell within the limits of agreement suggesting that the methods provide comparable intakes of these nutrients. The cross-classification of mean energy and nutrient intakes reported by the two methods are displayed in Table 3. The percentage of participants classified in "exact agreement" category of intake by both methods varied from $26 \%$ (\% energy from saturated fat) to $74 \%$ (zinc). The majority of participants were classified in the "exact agreement and adjacent" category of intake by both methods with percentages varying from $69 \%$ (carotene) to $92 \%$ (zinc, potassium, and sodium). The percentages of participants that were classified into the "extreme disagreement" were low; and for some nutrients (protein, niacin, potassium, and sodium), no participants were classified into this category. 
Table 3. Cross-classification of quartiles of mean energy and nutrient intake derived from Foodbook 24 and a 4 -day semi-weighed food diary.

\begin{tabular}{|c|c|c|c|c|}
\hline Nutrient & $\begin{array}{l}\text { Exact agreement } \\
(\%)^{\mathrm{a}}\end{array}$ & $\begin{array}{l}\text { Exact agreement and adjacent } \\
(\%)^{\mathrm{b}}\end{array}$ & $\begin{array}{l}\text { Disagreement } \\
(\%)^{\mathrm{c}}\end{array}$ & $\begin{array}{l}\text { Extreme disagreement } \\
(\%)^{\mathrm{d}}\end{array}$ \\
\hline Energy (kcal/d) & 46.2 & 84.6 & 7.7 & 7.7 \\
\hline$\%$ Energy carbohydrate & 30.8 & 76.9 & 20.5 & 2.6 \\
\hline$\%$ Energy protein & 41.0 & 84.6 & 12.8 & 2.6 \\
\hline$\%$ Energy saturated fat & 26.3 & 73.7 & 21.1 & 5.3 \\
\hline Protein (g/d) & 56.4 & 84.6 & 7.7 & 0 \\
\hline Carbohydrate (g/d) & 46.2 & 82.1 & 10.3 & 7.7 \\
\hline Sugars $(g / d)$ & 33.3 & 79.5 & 12.8 & 7.7 \\
\hline Dietary fiber (g/d) & 41.0 & 79.5 & 17.9 & 2.6 \\
\hline Fat $(g / d)$ & 38.5 & 74.4 & 17.9 & 7.7 \\
\hline Saturated fat (g/d) & 43.6 & 76.9 & 17.9 & 5.1 \\
\hline Monounsaturated fat (g/d) & 33.3 & 74.4 & 20.5 & 5.1 \\
\hline Polyunsaturated fat (g/d) & 43.6 & 79.5 & 15.4 & 5.1 \\
\hline Retinol ( $\mu \mathrm{g} / \mathrm{d})$ & 30.8 & 71.8 & 20.5 & 7.7 \\
\hline Carotene $(\mu \mathrm{g} / \mathrm{d})$ & 35.0 & 69.2 & 28.2 & 2.6 \\
\hline Vitamin D $(\mu \mathrm{g} / \mathrm{d})$ & 33.3 & 87.2 & 10.3 & 2.6 \\
\hline Vitamin E (mg/d) & 38.5 & 82.1 & 15.4 & 2.6 \\
\hline Riboflavin (mg/d) & 43.6 & 83.7 & 12.8 & 2.6 \\
\hline Vitamin B6 (mg/d) & 41.0 & 84.6 & 12.8 & 2.6 \\
\hline Vitamin B12 $(\mu \mathrm{g} / \mathrm{d})$ & 28.2 & 82.1 & 10.3 & 7.7 \\
\hline Folate $(\mu \mathrm{g} / \mathrm{d})$ & 46.2 & 84.6 & 12.8 & 2.6 \\
\hline Vitamin C (mg/d) & 41.0 & 79.5 & 12.8 & 7.7 \\
\hline Calcium (mg/d) & 35.9 & 79.5 & 15.4 & 5.1 \\
\hline Magnesium (mg/d) & 41.0 & 84.6 & 12.8 & 2.6 \\
\hline Iron (mg/d) & 38.5 & 79.5 & 17.9 & 2.6 \\
\hline Copper (mg/d) & 38.5 & 82.1 & 15.4 & 2.6 \\
\hline Zinc (mg/d) & 74.4 & 92.3 & 5.1 & 2.6 \\
\hline Potassium (mg/d) & 51.3 & 92.3 & 7.7 & 0 \\
\hline Sodium (mg/d) & 46.2 & 92.3 & 7.7 & 0 \\
\hline
\end{tabular}

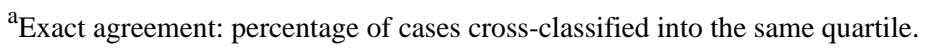

${ }^{b}$ Exact agreement and adjacent: percentage of cases cross-classified into the same or adjacent quartile.

${ }^{\mathrm{c}}$ Disagreement: percentage of cases cross-classified 2 quartiles apart.

${ }^{\mathrm{d}}$ Extreme disagreement: percentage of cases cross-classified 3 quartiles apart. 
Figure 4. Bland and Altman plot examining the mean difference in reporting of energy intake by the two methods.

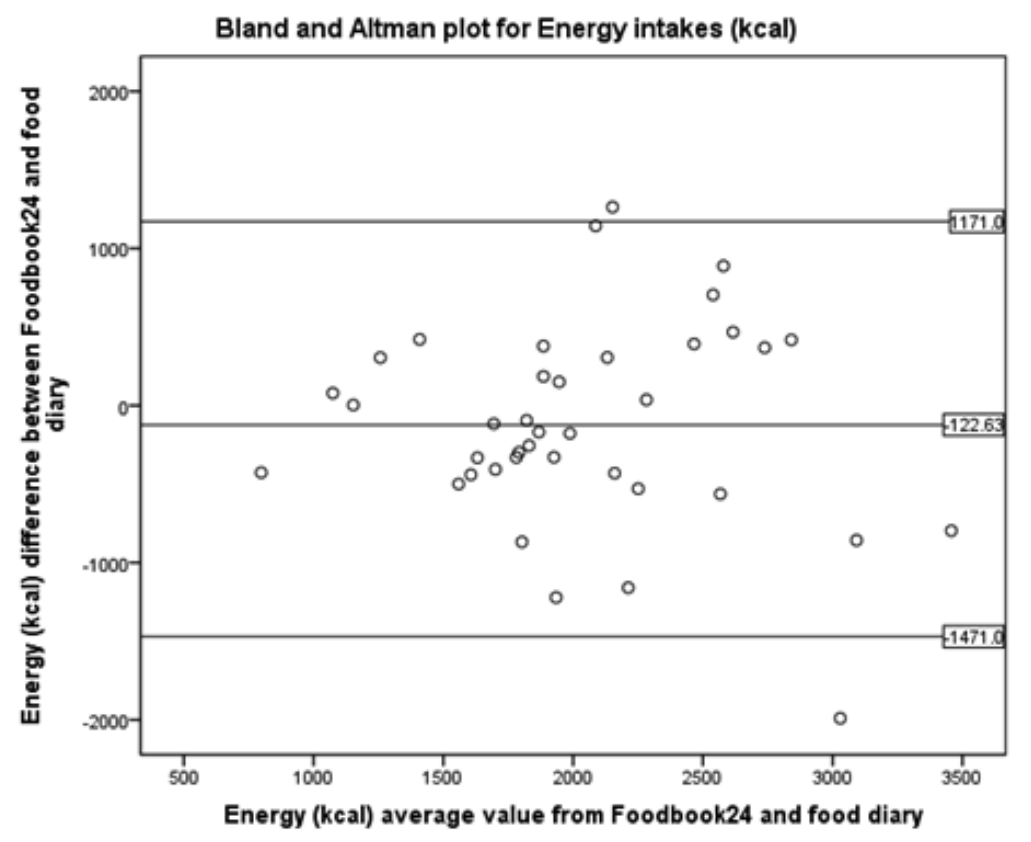

Figure 5. Bland and Altman plot examining the mean difference in reporting of carbohydrate intake by the two methods.

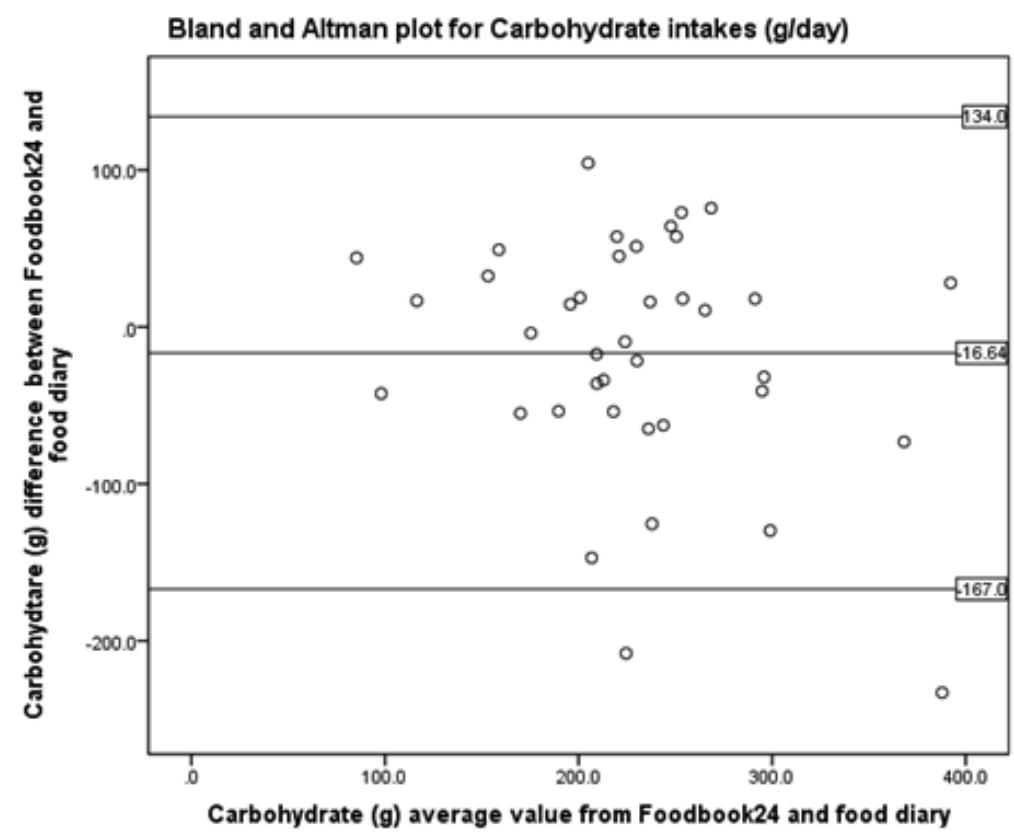


Figure 6. Bland and Altman plot examining the mean difference in reporting of protein intake by the two methods.

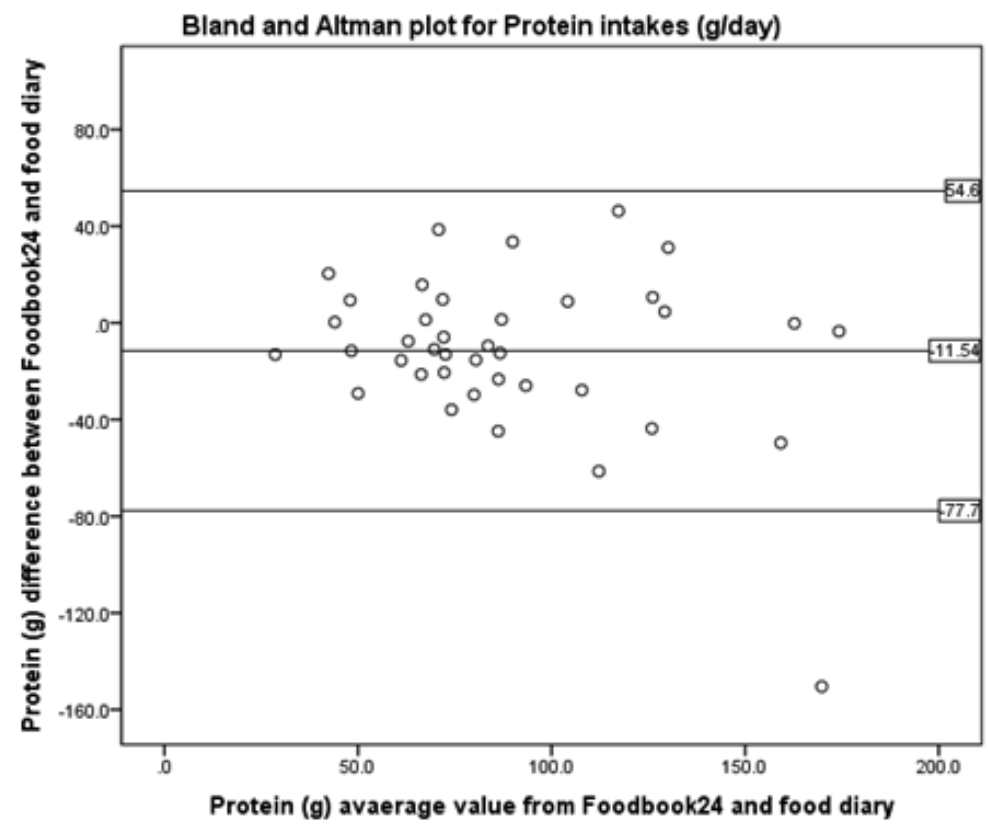

Figure 7. Bland and Altman plot examining the mean difference in reporting of fat intake by the two methods.

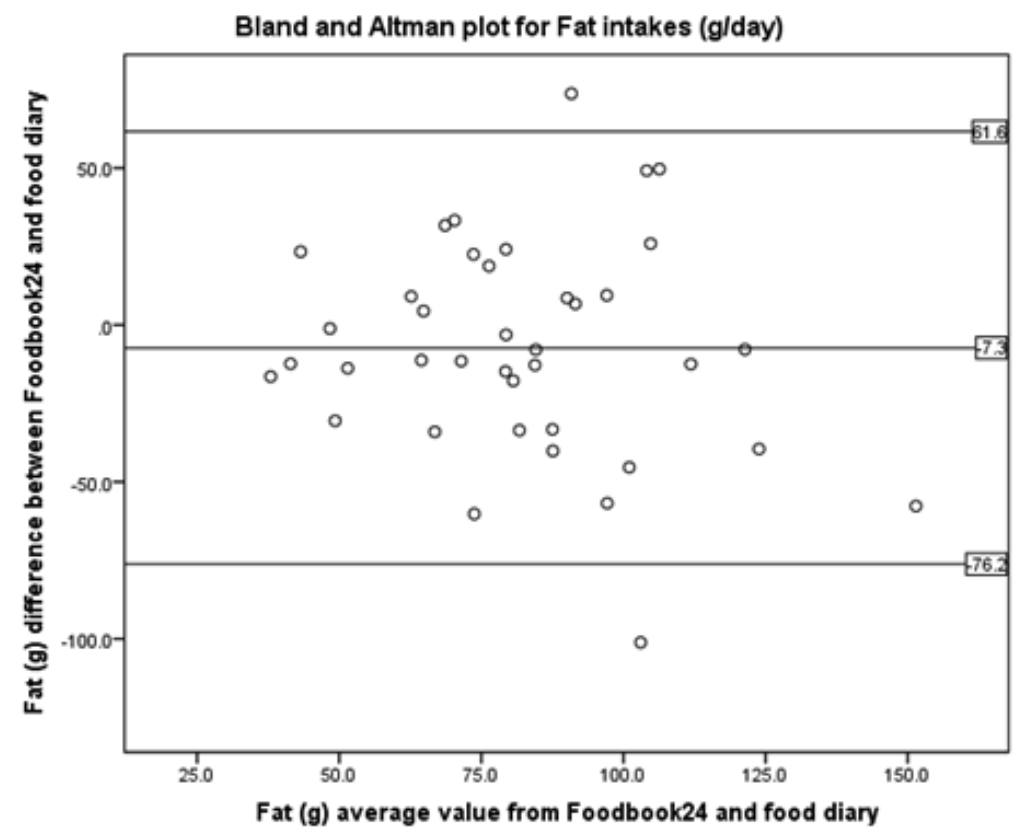


Figure 8. Bland and Altman plot examining the mean difference in reporting of fiber intake by the two methods.

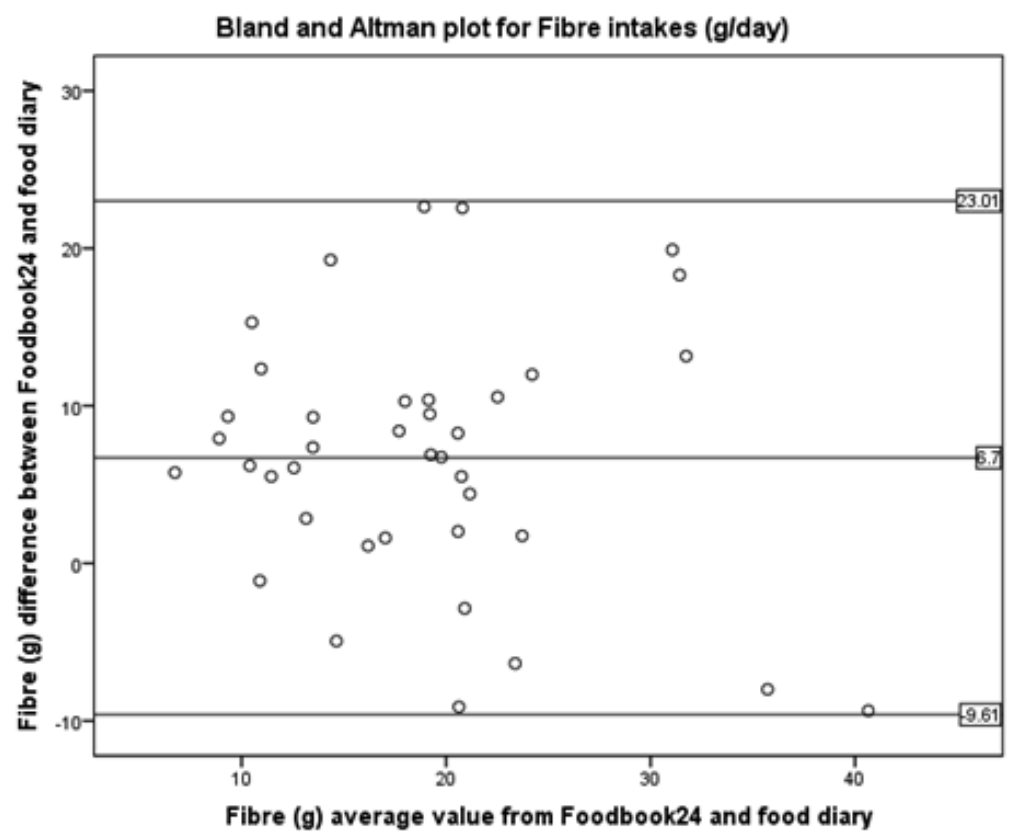

\section{Comparison of Food Group Intakes Reported by Both Methods of Dietary Assessment}

The mean food group intakes reported by both methods and the significant difference in the reporting of food group intake between the methods is presented in Table 2. Of the 19 food groups investigated, there were significant differences between the reporting of 6 food groups including "fruit and fruit dishes," "alcoholic beverages," and "sugars and confectionary, preserves, and savory snacks." The cross-classification of mean food group intakes reported by the two methods is displayed in Table 4. The percentage of participants classified in "exact agreement" category of intake by both methods varied from $25.6 \%$ ("sugars, confectionary, preserves, and savory snacks" and "soups, sauces, and miscellaneous foods") to $79 \%$ ("creams, ice creams, and desserts"). The majority of participants were classified in the "exact agreement and adjacent" category of intake by both methods; however, in the "creams, ice creams, and desserts" food group, no participants were classified into this category. Similar to the results for nutrients intakes, the percentages of participants that were classified into the "extreme disagreement" were low; and for some food groups (eg, alcoholic beverages), no participants were classified into this category.

\section{Comparison of Biological Markers of Intake Against Food and Nutrient Intake Reported by Methods of Dietary Assessment}

The relationships between urinary (recovery) and plasma (concentration) biomarkers and nutrient and food group intake recorded by both methods are reported in Table 5. Despite the researcher's best efforts to recruit individuals that did not take supplements, this was not possible in every case. The researchers did ask participants not to take nutritional supplements during the study, where possible. As a result, participants who reported taking supplements, including protein, multivitamin, vitamin, mineral and/or fish oil, before the provision of blood and urine samples during this study were excluded from analysis. This excluded 15 participants from plasma biomarker analysis (resulting in $\mathrm{n}=24$ for plasma biomarker analysis) and 11 participants from urinary biomarker analysis (resulting in $n=28$ for urinary biomarker analysis). With the exception of comparison of fruit and vegetable intakes $(\mathrm{g} / \mathrm{d})$ derived from Foodbook24 and total plasma carotenoids $(r=.315, \mathrm{n}=28, P=.10)$, there were good, significant correlations ( $r=.42$ to .64$)$ between food group and nutrient intakes reported by Foodbook 24 and biomarkers of nutrient and food group intake from plasma and urine samples. Nutrient and food group intakes derived from the semi-weighed food diary compared with biomarkers from urine and plasma samples resulted in strong, significant correlations except in the case of urinary potassium. 
Table 4. Cross-classification of quartiles of mean food group intake derived from Foodbook24 and a 4-day semi-weighed food diary.

\begin{tabular}{|c|c|c|c|c|}
\hline Food group & $\begin{array}{l}\text { Exact agreement } \\
(\%)^{\mathrm{a}}\end{array}$ & $\begin{array}{l}\text { Exact agreement and adjacent } \\
(\%)^{\mathrm{b}}\end{array}$ & $\begin{array}{l}\text { Disagreement } \\
(\%)^{\mathrm{c}}\end{array}$ & $\begin{array}{l}\text { Extreme disagreement } \\
(\%)^{\mathrm{d}}\end{array}$ \\
\hline Grains, rice, pasta, and savories & 43.6 & 71.8 & 17.9 & 10.3 \\
\hline Bread and rolls & 35.9 & 82.1 & 7.7 & 10.3 \\
\hline Breakfast cereals & 28.2 & 71.8 & 17.9 & 10.3 \\
\hline Biscuits, cakes, and pastries & 28.2 & 61.5 & 30.8 & 5.1 \\
\hline Milk and yogurt & 35.9 & 79.5 & 17.9 & 2.6 \\
\hline Creams, ice creams, and desserts & 79.5 & 0 & 20.5 & 0 \\
\hline Cheeses & 48.7 & 74.4 & 12.8 & 12.8 \\
\hline Butter, spreading fats, and oils & 38.5 & 66.7 & 25.6 & 7.7 \\
\hline Eggs and egg dishes & 48.7 & 71.8 & 25.6 & 2.6 \\
\hline Potatoes and potato dishes & 38.5 & 76.9 & 20.5 & 2.6 \\
\hline Veg and veg dishes & 46.2 & 87.2 & 10.3 & 2.6 \\
\hline Fruit and fruit dishes & 35.9 & 79.5 & 17.9 & 2.6 \\
\hline Fish and fish dishes & 51.3 & 79.5 & 20.5 & 0 \\
\hline Meat and meat products & 61.5 & 92.3 & 7.7 & 0 \\
\hline Alcoholic beverages & 63.2 & 15.8 & 21.0 & 0 \\
\hline Beverages other (sugar-sweetened) & 48.7 & 41.0 & 10.3 & 0 \\
\hline Sugars, confectionary, preserves, and savory snacks & 25.6 & 71.8 & 17.9 & 10.3 \\
\hline Soups, sauces, and miscellaneous foods & 25.6 & 76.9 & 12.8 & 10.3 \\
\hline Nuts, seeds, herbs, and spices & 35.9 & 74.4 & 17.9 & 7.7 \\
\hline
\end{tabular}

${ }^{a}$ Exact agreement: percentage of cases cross-classified into the same quartile.

${ }^{b}$ Exact agreement and adjacent: percentage of cases cross-classified into the same or adjacent quartile.

${ }^{\mathrm{c}}$ Disagreement: percentage of cases cross-classified 2 quartiles apart.

${ }^{\mathrm{d}}$ Extreme disagreement: percentage of cases cross-classified 3 quartiles apart. 
Table 5. Biomarker and food group relationship (as derived from Foodbook 24 and food diary).

\begin{tabular}{|c|c|c|c|}
\hline Biomarkers $^{\mathrm{a}}$ & Nutrient or food group ${ }^{b}$ & $\begin{array}{l}\text { Foodbook } 24 \text { correlation coefficient } \\
(r \text { value })^{\mathrm{c}}\end{array}$ & $\begin{array}{l}\text { Diary correlation coefficient } \\
(r \text { value })^{\mathrm{c}}\end{array}$ \\
\hline Concentration biomarkers & & $(n=28)$ & $(n=34)$ \\
\hline Plasma ascorbic acid $(\mu \mathrm{M})$ & Fruit and veg (g/d) & 0.421 & 0.505 \\
\hline Plasma total carotenoids $(\mu \mathrm{mol} / \mathrm{L})$ & Fruit and veg $(\mathrm{g} / \mathrm{d})$ & $0.315^{\mathrm{e}}$ & 0.671 \\
\hline Plasma omega-3 index & Fish (g/d) & 0.468 & 0.769 \\
\hline Plasma ascorbic acid $(\mu \mathrm{M})$ & Vitamin C (mg/d) & 0.518 & 0.605 \\
\hline Recovery biomarkers & & $(\mathrm{n}=34)$ & $(\mathrm{n}=33)$ \\
\hline Urinary urea $(\mathrm{mmol} / \mathrm{d})$ & Protein $(g / d)$ & 0.645 & 0.824 \\
\hline Urinary potassium $(\mathrm{mmol} / \mathrm{d})$ & Potassium (mg/d) & 0.542 & $0.269^{\mathrm{e}}$ \\
\hline Urinary sodium $(\mathrm{mmol} / \mathrm{d})^{\mathrm{d}}$ & Sodium $(\mathrm{mg} / \mathrm{d})$ & 0.56 & 0.476 \\
\hline
\end{tabular}

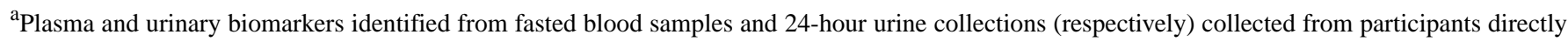
after recording intake using either dietary assessment methods.

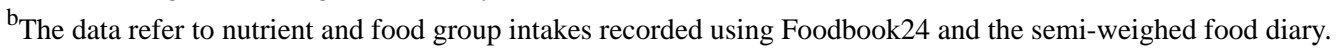

${ }^{\mathrm{c}}$ Spearman correlation coefficient.

${ }^{\mathrm{d}}$ Sodium excretion measures were corrected to account for $90 \%$ excretion of all sodium consumed (28).

${ }^{\mathrm{e}}$ Not statistically significant correlations $(P<.05)$.

\section{User Evaluation of Foodbook24}

The main results of participants' evaluation of the 24-hour recall component of Foodbook 24 are depicted in Table 6 . The majority of respondents were very positive in their evaluation of Foodbook24. Overall, the majority found the Foodbook24 system user-friendly with $69.5 \%(82 / 118)$ reporting it easy or
"OK" to use. When asked if participants felt that Foodbook24 changed what they ate and drank, a majority of $62.7 \%(74 / 118)$ felt it did not change at all, whereas $34.7 \%$ (41/118) felt it changed it a little, and 2.5\% (3/118) felt it changed a lot. Importantly, when asked if there were any foods or drinks that participants did not want to record, a majority of $95.8 \%$ (113/118) stated "no."

Table 6. Participant acceptability of Foodbook 24.

\begin{tabular}{|c|c|c|c|c|}
\hline Question posed to participant & Participant response & & & \\
\hline \multirow[t]{2}{*}{ Impact of Foodbook24 on diet } & Changed a lot $(\%)$ & Changed a little (\%) & Did not change at all (\%) & \\
\hline & 2.5 & 34.7 & 62.7 & \\
\hline \multirow[t]{2}{*}{ Completion time } & Too long (\%) & Okay $(\%)$ & Short $(\%)$ & Very short $(\%)$ \\
\hline & 6.8 & 63.6 & 22.9 & 6.8 \\
\hline \multirow[t]{2}{*}{ User friendliness } & Difficult $(\%)$ & Okay $(\%)$ & Easy $(\%)$ & Very easy $(\%)$ \\
\hline & 3.4 & 33.1 & 36.4 & 27.4 \\
\hline \multirow[t]{2}{*}{ Remembering to use Foodbook24 } & Difficult (\%) & Okay (\%) & Easy $(\%)$ & Very easy $(\%)$ \\
\hline & 6.8 & 38.1 & 40.7 & 14.4 \\
\hline \multirow[t]{2}{*}{ Preferred method } & Foodbook24 (\%) & Reference method $^{\mathrm{a}}(\%)$ & Other $(\%)$ & \\
\hline & 67.8 & 31.4 & 0.8 & \\
\hline \multirow[t]{2}{*}{ Use Foodbook24 for longer } & 1 week $(\%)$ & 1 month (\%) & 6 months $(\%)$ & No $(\%)$ \\
\hline & 27.1 & 30.5 & 24.6 & 17.8 \\
\hline
\end{tabular}

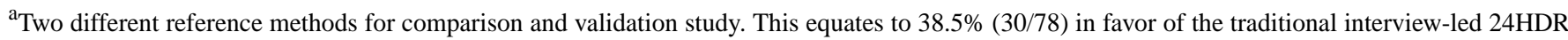
and $17.5 \%(7 / 40)$ for semi-weighed food diary.

Participants were asked about using Foodbook24 for longer periods of time to gain insight into the potential long-term use of the tool. The results were favorable for the shorter time of a week (considering the completion of two 24-hour recalls per week) with $82.2 \%$ willing to use Foodbook24 for a week, persistence understandably decreased with $55.1 \%$ willing to use for a month, and $24.6 \%$ for 6 months. When asked to select which method participants would prefer to use in future 
(Foodbook24 vs the respective reference method), $67.8 \%$ (80/118) opted for Foodbook24 and 31.4\% (27/118) for the reference method. The researchers were aware that these particular results may have been influenced by the different reference method used in either study (interviewer-led 24HDR in the comparison study and a 4-day semi-weighed food diary in the validation study). The participant burden associated with a 4-day semi-weighed food diary may have been greater than that of an interview-led 24HDR. As a result, responses were split by study involvement. A majority of $61.5 \%$ (48/78) opted for Foodbook24 when compared with 38.5\% (30/78) in favor of the interview-led 24HDR. Foodbook24 was an even clearer preference when compared with the semi-weighed food diary with $80 \%$ (32/40) in favor of Foodbook24 as opposed to $17.5 \%$ (7/40) for semi-weighed food diary and 1 participant $(2.5 \%)$ opted for "other."

\section{Discussion}

\section{Principal Findings}

As far as the researchers are aware, Foodbook24 is the first Web-based dietary assessment tool developed to estimate food and nutrient intakes specifically for Irish adults. The results of this investigation into the validity of Foodbook 24 suggest that the tool provides nutrient and food group intake estimates comparable with that of a semi-weighed food diary. The use of an objective measure of validity; biological markers of nutrient intake in blood and urine samples further confirm this agreement between methods.

With regards to food group intake, the results of the paired $t$ test and cross-classification analysis indicate that there is good agreement between the two methods in the reporting of the majority of food group intakes. Interestingly Foodbook24 reported higher intakes of food groups that are perceived unhealthy such as "alcoholic beverages" and "sugars and confectionary" compared with the food diary. This may be due to variation in diet as was the case for fiber intakes. However, the lack of face-to-face interaction between participant and researcher that is encountered on the completion of a food record (food record review with researcher) may encourage participants of Foodbook24 to report their intake with less inhibition or in a less inhibited manner [33,34]. This may highlight an advantage of Web-based dietary assessment in terms of attenuating the influence of social desirability when self-reporting dietary intake. A study conducted by Probst and Tapsell [35] found that patients using a computer to self-report intake were more willing to report all foods eaten to the computer than to a dietitian. Intakes of "milk and yogurt" were lower with Foodbook24 compared with the food diary, although these differences were not statistically significant. Although milk was a linked food (to prompt the participant to record milk with items such as cereal and hot beverages), it may be the case that milk consumed as a beverage was frequently forgotten when recording dietary intake using Foodbook24.

Overall for nutrient intakes, correlations were acceptable to very good; however, there were few significant differences between nutrient intakes reported using Foodbook24 and the semi-weighed food diary. The correlation ranges observed were also comparable with other studies investigating the validity of Web-based 24-hour recall methods [36-39]. There were, however, nutrients that were not correlated such as the intakes of monounsaturated fat and intakes that were significantly different from the semi-weighed food diary, for example, protein and fiber. In an evaluation of the shortened food-list $(n=751)$ for integration into Foodbook24 [20], it was observed that there was less agreement for mean daily intake of monounsaturated and saturated fat due to the changes in food composition data that resulted from merging similar food and drink items that had similar composition into single food or drink descriptors or codes. Expanding the number of food items within this category may improve the agreement between methods for these nutrients.

Foodbook24 reported lower intakes of protein compared with the semi-weighed food diary, potentially due to different portion size estimations (portion size photographs using Foodbook24 compared with free weight entry using semi-weighed food diary). The within-person variance (ie, day-to-day variation in diet) during the two different data collection time points also accounted for the differences of intakes reported by both methods for fiber. Food items with high fiber content, for example, baked beans in tomato sauce, fruit smoothies, and breakfast cereals were more frequently reported by participants recording dietary intake using Foodbook24 than with the food diary. The challenges of the variation of diet during dietary assessment validation whereby two separate methods (the test and references measure) assess dietary intakes over two different time points have been noted by others [40,41]. However, despite the differences in fiber intake recorded, none of the cases fell outside of the limits of agreement in the Bland and Altman plot for fiber intake (Figure 8) suggesting that there may be an acceptable level of agreement between the two methods.

Biological markers of nutrient intake can serve as an objective validation of dietary assessment methods as they reflect nutritional status, metabolism, and recent dietary intake, but the error associated with biological markers is independent of dietary intake assessment error [42]. Urinary urea excretion was used as an independent marker of protein intake in this study as it can be assumed that urinary urea is excreted in constant proportion to urinary nitrogen for individuals in energy balance and consuming a westernized diet [26]. Overall, a slightly stronger correlation was observed for intakes derived from the food diary compared with Foodbook24, but this was to be expected considering more accurate portion size assessment observed with semi-weighed food records [43]. Dietary intakes recorded by both methods correlated significantly with recovery biomarkers (urinary urea, potassium, and sodium) with the exception of urinary potassium, which did not significantly correlate with potassium intakes reported from the food diary but did with dietary intakes reported from Foodbook24. This was an unexpected, but promising finding considering potassium is present in a large variety of food groups and is considered a reliable recovery biomarker in dietary studies [44]. Concentration biomarkers can be used to assess which assessment method yielded the most reliable estimates of intakes [45]. The food diary provided more reliable intakes of fish intake and total carotenoids, but estimates were similar for fruit and 
vegetable intake and ascorbic acid suggesting that both methods are valid and comparable in the reporting of these dietary components. The correlation coefficients between nutrient intakes and biomarkers of nutrient intakes reported in this study are comparable with those reported in other validation studies [46-48], although the correlations between protein intake and urinary urea observed in this study were stronger than those reported in the pooled results from 5 validation studies of dietary self-report instruments [49]. The pooled results study reported an average correlation coefficient for reported protein intakes versus true protein intakes of $r=.29$ when assessed using an FFQ and $r=.48$ when assessed using the average of three 24-hour recalls. However, urinary nitrogen was used as a biomarker of protein intake for these studies so that a direct comparison cannot be made. Overall, these results indicate that self-administered 24HDR via Foodbook24 provide estimates of certain nutrients and fruit and vegetable intakes similar to that of a 4-day semi-weighed food diary.

The majority of participants who used Foodbook24 were enthusiastic in their evaluation of the Web-based tool, and a large proportion of respondents claimed that they would be willing to use Foodbook24 for a week. Freese et al [50] reported similar positive responses where $95 \%$ of 370 adult participants would be willing to repeat the Web-based 24HDR after completing 3 recalls. In contrast, Maes et al [31] reported that adolescent participants involved in the HELENA (Healthy Lifestyle in Europe by Nutrition in Adolescence) "Food-O-Meter" project were not eager to use their computer-based FFQ more than once. Most importantly, Foodbook24 was the preferred method of dietary intake assessment for the majority of participants. Vereecken et al [51] reported a similar preference for an online method with $73 \%$ of parents in the Children's and Adolescents' Nutrition Assessment and Advice on the Web (CANAA-W) study stating that they preferred a 3-day computerized food record over the paper and pencil 3-day food record (12\%), whereas $10 \%$ selected a computerized FFQ and 6\% selected a paper and pencil FFQ. Similarly, Monnerie et al [52] reported a 77\% (77/100) preference for online assessment versus a traditional diary over 7 days. Thompson et al [53] also observed a clear participant preference for ASA24 when compared with the traditional interviewer administered method across a range of age groups (20-70 years) and education levels. This may highlight a willingness among Irish adults to record their dietary intake with the aid of technology and as such offers hope that Web-based methods can act as a viable alternative or accompaniment to nutritional surveillance in Ireland. Future research is required to ascertain the actual potential for Web-based innovations to work in tandem with current methods in nutritional surveillance.

\section{Strengths and Limitations}

Although this study has many strengths including the use of biomarkers of intake in the tool validation and the inclusion of nationally representative food intake data in the tool design, it is also important to consider the study limitations. The small sample size recruited was a limitation of this study and the exclusion of participants that took nutritional supplements further reduced numbers for certain aspects of analysis. Unfortunately, high dropout rates as observed with this study are commonly reported in studies that require participants to provide biological samples on more than one occasion, particularly 24-hour urine collections. With regards to the analysis of urine samples, the use of urinary nitrogen and para-aminobenzoic acid ( $P A B A)$ would have been preferable as an objective measure of protein intake and as a check for completeness of collection, respectively; however, these measurements were not possible for this study. Finally, the majority of participants recruited as part of the validation study and in other studies evaluating Foodbook24 were young, healthy, and motivated individuals, and therefore may not represent the opinions of the general adult population with respects to their ability to use Foodbook 24 and their preference of dietary assessment methods. To further evaluate Foodbook24, a proof-of-principle (PoP) study that involves Foodbook24 being made freely available to the general Irish adult population is currently underway. The PoP study will provide insight into the acceptability of Foodbook24 with a more representative sample of the general Irish adult population.

\section{Conclusions}

In this paper, we investigated the relative validity of a Web-based 24HDR tool, Foodbook24. Although this study only investigates the validity of the 24HDR component of the Foodbook 24 tool, the tool itself incorporates the use of blended assessment methods that has the potential to yield more accurate data on habitual intake [5]. This study describes the robust validation of Foodbook24 against a semi-weighed food diary and biological markers of nutrient and food group intake. The results from this study demonstrate that Foodbook 24 performs well when compared with a semi-weighed food diary and provides comparable estimates of food and nutrient intakes. A major advantage of Foodbook24 and of similar Web-based dietary assessment tools is the reduced cost associated with the collection of dietary intake data compared with traditional methods. More importantly, Web-based methodologies facilitate the collection of data in a neutral environment, in the absence of a researcher with less burden for the participant which may encourage participants to report intake more honestly. Participant acceptability data gathered so far suggests Foodbook24 was well received by the majority of participants in this study sample which indicates the potential of Foodbook 24 for use in nutrition related research or as a means of intermittent data collection between national nutrition surveys in Ireland.

\section{Acknowledgments}

This research was completed as part of a Food Institutional Research Measure (FIRM) project, DietIreland, funded by the Department of Agriculture, Food and Marine (13/F/424). The researchers wish to acknowledge the participants who took part in the study and also Creme Global for developing the software for Foodbook24. 


\section{Conflicts of Interest}

None declared.

\section{Multimedia Appendix 1}

Daily energy and nutrient intakes recorded by participants using the Foodbook24 tool and a 4-day semi-weighed food diary.

[PDF File (Adobe PDF File), 46KB-Multimedia Appendix 1]

\section{References}

1. Thompson F, Subar A. Nutrition in the Prevention and Treatment of Disease. London: Elsevier; 2013.

2. MacIntyre U. Measuring Food Intake. In: Introduction to Human Nutrition - The Nutrition Society Textbook. Oxford: Wiley-Blackwell; 2002.

3. Walton J. Dietary assessment methodology for nutritional assessment. Top Clin Nutr 2015;30(1):33-46. [doi: 10.1097/TIN.0000000000000018]

4. Subar AF, Crafts J, Zimmerman TP, Wilson M, Mittl B, Islam NG, et al. Assessment of the accuracy of portion size reports using computer-based food photographs aids in the development of an automated self-administered 24-hour recall. J Am Diet Assoc 2010 Jan;110(1):55-64 [FREE Full text] [doi: 10.1016/j.jada.2009.10.007] [Medline: 20102828]

5. Illner A, Freisling H, Boeing H, Huybrechts I, Crispim SP, Slimani N. Review and evaluation of innovative technologies for measuring diet in nutritional epidemiology. Int J Epidemiol 2012 Aug;41(4):1187-1203 [FREE Full text] [doi: 10.1093/ije/dys 105] [Medline: 22933652]

6. Fallaize R, Forster H, Macready AL, Walsh MC, Mathers JC, Brennan L, et al. Online dietary intake estimation: reproducibility and validity of the Food4Me food frequency questionnaire against a 4-day weighed food record. J Med Internet Res 2014 Aug;16(8):e190 [FREE Full text] [doi: 10.2196/jmir.3355] [Medline: 25113936]

7. Slimani N, Casagrande C, Nicolas G, Freisling H, Huybrechts I, Ocké MC, et al. The standardized computerized 24-h dietary recall method EPIC-Soft adapted for pan-European dietary monitoring. Eur J Clin Nutr 2011 Jul;65 Suppl 1:S5-15. [doi: 10.1038/ejen.2011.83] [Medline: 21731006]

8. Boushey CJ, Kerr DA, Wright J, Lutes KD, Ebert DS, Delp EJ. Use of technology in children's dietary assessment. Eur J Clin Nutr 2009 Feb;63:S50-S57 [FREE Full text] [doi: 10.1038/ejcn.2008.65]

9. Touvier M, Kesse-Guyot E, Méjean C, Pollet C, Malon A, Castetbon K, et al. Comparison between an interactive web-based self-administered $24 \mathrm{~h}$ dietary record and an interview by a dietitian for large-scale epidemiological studies. Br J Nutr 2011 Apr;105(7):1055-1064. [doi: 10.1017/S0007114510004617] [Medline: 21080983]

10. Margetts B, Nelson M. Design concepts in nutritional epidemiology. Oxford: Oxford University Press; 1997.

11. McCabe-Sellers B. Advancing the art and science of dietary assessment through technology. J Am Diet Assoc 2010 Jan;110(1):52-54. [doi: 10.1016/j.jada.2009.10.014] [Medline: 20102827]

12. Diep C, Hingle M, Chen T, Dadabhoy H, Beltran A, Baranowski J. The automated self-administered 24-hour dietary recall for children, 2012 version, for youth aged 9 to 11 years: a validation study. J Acad Nutr Diet 2012;115(10):1591-1598. [doi: 10.1016/j.jand.2015.02.021]

13. Kirkpatrick SI, Subar AF, Douglass D, Zimmerman TP, Thompson FE, Kahle LL, et al. Performance of the automated aelf-administered 24-hour recall relative to a measure of true intakes and to an interviewer-administered 24-h recall. Am J Clin Nutr 2014 Jul;100(1):233-240 [FREE Full text] [doi: 10.3945/ajcn.114.083238] [Medline: 24787491]

14. Burrows TL, Khambalia AZ, Perry R, Carty D, Hendrie GA, Allman-Farinelli MA, et al. Great 'app-eal' but not there yet: a review of iPhone nutrition applications relevant to child weight management. Nutr Diet 2015 Apr 16;72(4):363-367. [doi: 10.1111/1747-0080.12184]

15. European Food Safety Authority. General principles for the collection of national food consumption data in the view of a pan-European dietary survey. EFSA Journal 2009 Dec 18;7(12):1435. [doi: 10.2903/j.efsa.2009.1435]

16. Moshfegh A, Raper N, Ingwersen L. An improved approach to 24-hour dietary recall methodology. Ann Nutr Metab (suppl) 2001;45:156.

17. Irish Universities Nutrition Alliance. 2010. National adult nutrition survey: summary report URL: http://www.iuna.net/ [accessed 2016-07-25] [WebCite Cache ID 6jGbgac8E]

18. McCance RA, Widdowson EM. McCance and Widdowsons The Composition of Foods. Cambridge: Royal Society of Chemistry; 2002.

19. Black L, Ireland J, Møller A, Roe M, Walton J, Flynn A, et al. Development of an on-line Irish food composition database for nutrients. J Food Comp Anal 2011 Nov;24(7):1017-1023. [doi: 10.1016/j.jfca.2011.01.015]

20. Evans K, Hennessy A, Timon C, Walton J, Gibney E, Flynn A. Development of a short food list for use in a web-based dietary assessment tool. In: Ann Nutr Metab. 2015 Presented at: 12th FENS European Nutrition Conference; October 2015; Berlin p. 214. 
21. Foster E. Final Report for Food Standards Agency. Comparison study: INTAKE24 vs Interviewer led recall URL: http:/ /webarchive.nationalarchives.gov.uk/+/http://www.food.gov.uk/scotland/news-updates/news/2014/13135/intake24 [accessed 2016-11-04] [WebCite Cache ID 6llphUnFa]

22. Mills A, Patel S. Food Standards Agency. In: Food Portion Sizes. London: TSO; 1993.

23. Bingham SA, Gill C, Welch A, Cassidy A, Runswick SA, Oakes S, et al. Validation of dietary assessment methods in the UK arm of EPIC using weighed records, and 24-hour urinary nitrogen and potassium and serum vitamin C and carotenoids as biomarkers. Int J Epidemiol 1997;26 Suppl 1:S137-S151 [FREE Full text] [Medline: 9126542]

24. Steptoe A, Pollard TM, Wardle J. Development of a measure of the motives underlying the selection of food: the food choice questionnaire. Appetite 1995 Dec;25(3):267-284. [doi: 10.1006/appe.1995.0061] [Medline: 8746966]

25. Nicholson S, Cox L, Mistry P. Food. NDNS appendix T: the 24-hour urine sample: collecting and processing the urine and assessment of completeness of collection URL: https://www.food.gov.uk/sites/default/files/ndns-appendix-t-ni.pdf [accessed 2016-11-17] [WebCite Cache ID 6m5ofdQif]

26. Bingham SA, Williams R, Cole TJ, Price CP, Cummings JH. Reference values for analytes of 24-h urine collections known to be complete. Ann Clin Biochem 1988 Nov;25:610-619. [Medline: 3267076]

27. Joossens J, Geboers J. Surveillance of dietary habits of the population with regard to cardiovascular diseases: validity and reproducibility of methods. In: Euro-Nut Report 2: A concerted action project on nutrition in the European Community. Wageningen, The Netherlands: Department of Human Nutrition, Agricultural University; 1984.

28. Mercado CI, Cogswell ME, Valderrama AL, Wang C, Loria CM, Moshfegh AJ, et al. Difference between 24-h diet recall and urine excretion for assessing population sodium and potassium intake in adults aged 18-39 y. Am J Clin Nutr 2015 Feb;101(2):376-386 [FREE Full text] [doi: 10.3945/ajcn.113.081604] [Medline: 25646336]

29. Bland M. An introduction to medical statistics. Oxford: Oxford University Press; 2000.

30. Bland JM, Altman DG. Statistical methods for assessing agreement between two methods of clinical measurement. Lancet 1986 Feb 8;1(8476):307-310. [Medline: 2868172]

31. Maes L, Cook TL, Ottovaere C, Matthijs C, Moreno LA, Kersting M, et al. Pilot evaluation of the HELENA (healthy lifestyle in europe by nutrition in adolescence) food-o-meter, a computer-tailored nutrition advice for adolescents: a study in six European cities. Public Health Nutr 2011 Jul;14(7):1292-1302. [doi: 10.1017/S1368980010003563] [Medline: 21281542]

32. Vereecken C, Covents M, Maes L, Moyson T. Formative evaluation of the dietary assessment component of children's and adolescents' nutrition assessment and advice on the web (CANAA-W). J Hum Nutr Diet 2014 Jan;27 Suppl 1:54-65. [doi: 10.1111/j.1365-277X.2012.01290.x] [Medline: 23980931]

33. van Gelder Marleen MH, Bretveld RW, Roeleveld N. Web-based questionnaires: the future in epidemiology? Am J Epidemiol 2010 Dec 1;172(11):1292-1298 [FREE Full text] [doi: 10.1093/aje/kwq291] [Medline: 20880962]

34. Mathieu E, Barratt A, Carter SM, Jamtvedt G. Internet trials: participant experiences and perspectives. BMC Med Res Methodol 2012 Oct 23;12:162 [FREE Full text] [doi: 10.1186/1471-2288-12-162] [Medline: 23092116]

35. Probst Y, Tapsell L. Over- and underreporting of energy intake by patients with metabolic syndrome using an automated dietary assessment website. Nutr Diet 2007 Dec;64(4):280-284. [doi: 10.1111/j.1747-0080.2007.00220.x]

36. De KW, Huybrechts I, De VV, Vandevijvere S, Slimani N, Van OH, et al. Repeated 24-hour recalls versus dietary records for estimating nutrient intakes in a national food consumption survey. Food Nutr Res 2011 Nov;55:7307 [FREE Full text] [doi: 10.3402/fnr.v55i0.7307] [Medline: 22084625]

37. Comrie F, Masson LF, McNeill G. A novel online Food Recall Checklist for use in an undergraduate student population: a comparison with diet diaries. Nutr J 2009 Feb 19;8:13 [FREE Full text] [doi: 10.1186/1475-2891-8-13] [Medline: 19228392]

38. Liu B, Young H, Crowe FL, Benson VS, Spencer EA, Key TJ, et al. Development and evaluation of the Oxford WebQ, a low-cost, web-based method for assessment of previous $24 \mathrm{~h}$ dietary intakes in large-scale prospective studies. Public Health Nutr 2011 Nov;14(11):1998-2005. [doi: 10.1017/S1368980011000942] [Medline: 21729481]

39. Zoellner J, Anderson J, Gould SM. Comparative validation of a bilingual interactive multimedia dietary assessment tool. J Am Diet Assoc 2005 Aug;105(8):1206-1214. [doi: 10.1016/j.jada.2005.05.011] [Medline: 16182635]

40. Labonté M, Cyr A, Baril-Gravel L, Royer M, Lamarche B. Validity and reproducibility of a web-based, self-administered food frequency questionnaire. Eur J Clin Nutr 2012 Feb;66(2):166-173. [doi: 10.1038/ejcn.2011.163] [Medline: 21934698]

41. Chan SG, Ho SC, Kreiger N, Darlington G, Adlaf EM, So KF, et al. Validation of a food frequency questionnaire for assessing dietary soy isoflavone intake among midlife Chinese women in Hong Kong. J Nutr 2008 Mar;138(3):567-573 [FREE Full text] [Medline: 18287368]

42. McKeown NM, Day NE, Welch AA, Runswick SA, Luben RN, Mulligan AA, et al. Use of biological markers to validate self-reported dietary intake in a random sample of the European Prospective Investigation into Cancer United Kingdom Norfolk cohort. Am J Clin Nutr 2001 Aug;74(2):188-196 [FREE Full text] [Medline: 11470719]

43. Bingham SA, Gill C, Welch A, Day K, Cassidy A, Khaw KT, et al. Comparison of dietary assessment methods in nutritional epidemiology: weighed records v. $24 \mathrm{~h}$ recalls, food-frequency questionnaires and estimated-diet records. Br J Nutr 1994 Oct;72(4):619-643. [Medline: 7986792] 
44. Tasevska N, Runswick SA, Bingham SA. Urinary potassium is as reliable as urinary nitrogen for use as a recovery biomarker in dietary studies of free living individuals. J Nutr 2006 May;136(5):1334-1340 [FREE Full text] [Medline: 16614426]

45. Bingham S, Luben R, Welch A, Low YL, Khaw KT, Wareham N, et al. Associations between dietary methods and biomarkers, and between fruits and vegetables and risk of ischaemic heart disease, in the EPIC Norfolk Cohort Study. Int J Epidemiol 2008 Oct;37(5):978-987 [FREE Full text] [doi: 10.1093/ije/dyn111] [Medline: 18579574]

46. Lassale C, Castetbon K, Laporte F, Camilleri GM, Deschamps V, Vernay M, et al. Validation of a Web-based, self-administered, non-consecutive-day dietary record tool against urinary biomarkers. Br J Nutr 2015 Mar 28;113(6):953-962. [doi: 10.1017/S0007114515000057] [Medline: 25772032]

47. Timon CM, Astell AJ, Hwang F, Adlam TD, Smith T, Maclean L, et al. The validation of a computer-based food record for older adults: the novel assessment of nutrition and ageing (NANA) method. Br J Nutr 2015 Feb 28;113(4):654-664. [doi: 10.1017/S0007114514003808] [Medline: 25630436]

48. Patterson AC, Hogg RC, Kishi DM, Stark KD. Biomarker and dietary validation of a Canadian food frequency questionnaire to measure eicosapentaenoic and docosahexaenoic acid intakes from whole food, functional food, and nutraceutical sources. J Acad Nutr Diet 2012 Jul;112(7):1005-1014. [doi: 10.1016/j.jand.2012.03.030] [Medline: 22583924]

49. Freedman LS, Commins JM, Moler JE, Arab L, Baer DJ, Kipnis V, et al. Pooled results from 5 validation studies of dietary self-report instruments using recovery biomarkers for energy and protein intake. Am J Epidemiol 2014 Jul 15;180(2):172-188. [doi: 10.1093/aje/kwu116] [Medline: 24918187]

50. Freese J, Feller S, Harttig U, Kleiser C, Linseisen J, Fischer B, et al. Development and evaluation of a short 24-h food list as part of a blended dietary assessment strategy in large-scale cohort studies. Eur J Clin Nutr 2014 Mar;68(3):324-329. [doi: 10.1038/ejcn.2013.274] [Medline: 24398637]

51. Vereecken CA, Covents M, Haynie D, Maes L. Feasibility of the young children's nutrition assessment on the web. J Am Diet Assoc 2009 Nov;109(11):1896-1902. [doi: 10.1016/j.jada.2009.08.013] [Medline: 19857631]

52. Monnerie B, Tavoularis LG, Guelinckx I, Hebel P, Boisvieux T, Cousin A, et al. A cross-over study comparing an online versus a paper 7-day food record: focus on total water intake data and participant's perception of the records. Eur J Nutr 2015 Jun;54 Suppl 2:27-34 [FREE Full text] [doi: 10.1007/s00394-015-0945-7] [Medline: 26066355]

53. Thompson FE, Dixit-Joshi S, Potischman N, Dodd KW, Kirkpatrick SI, Kushi LH, et al. Comparison of interviewer-administered and automated self-administered 24-hour dietary recalls in 3 diverse integrated health systems. Am J Epidemiol 2015 Jun 15;181(12):970-978 [FREE Full text] [doi: 10.1093/aje/kwu467] [Medline: 25964261]
Abbreviations
ANOVA: analysis of variance
FFQ: food frequency questionnaire
24HDR: 24-hour dietary recall
RCF: relative centrifugal force
UCE: urinary creatinine excretion

Edited by G Eysenbach; submitted 26.07.16; peer-reviewed by A Subar, F Thompson, T Baranowski, J Sheats; comments to author
27.09.16; revised version received 18.11.16; accepted 11.02.17; published 11.05.17
Please cite as:
Timon CM, Blain RJ, McNulty B, Kehoe L, Evans K, Walton J, Flynn A, Gibney ER
The Development, Validation, and User Evaluation of Foodbook24: A Web-Based Dietary Assessment Tool Developed for the Irish
Adult Population
J Med Internet Res 2017;19(5):e158
URL: $\underline{\text { http://www.jmir.org/2017/5/e158/ }}$
doi: $\underline{10.2196 / j m i r .6407}$
PMID: $\underline{28495662}$

(C) Claire M Timon, Richard J Blain, Breige McNulty, Laura Kehoe, Katie Evans, Janette Walton, Albert Flynn, Eileen R Gibney. Originally published in the Journal of Medical Internet Research (http://www.jmir.org), 11.05.2017. This is an open-access article distributed under the terms of the Creative Commons Attribution License (http://creativecommons.org/licenses/by/2.0/), which permits unrestricted use, distribution, and reproduction in any medium, provided the original work, first published in the Journal of Medical Internet Research, is properly cited. The complete bibliographic information, a link to the original publication on http://www.jmir.org/, as well as this copyright and license information must be included. 